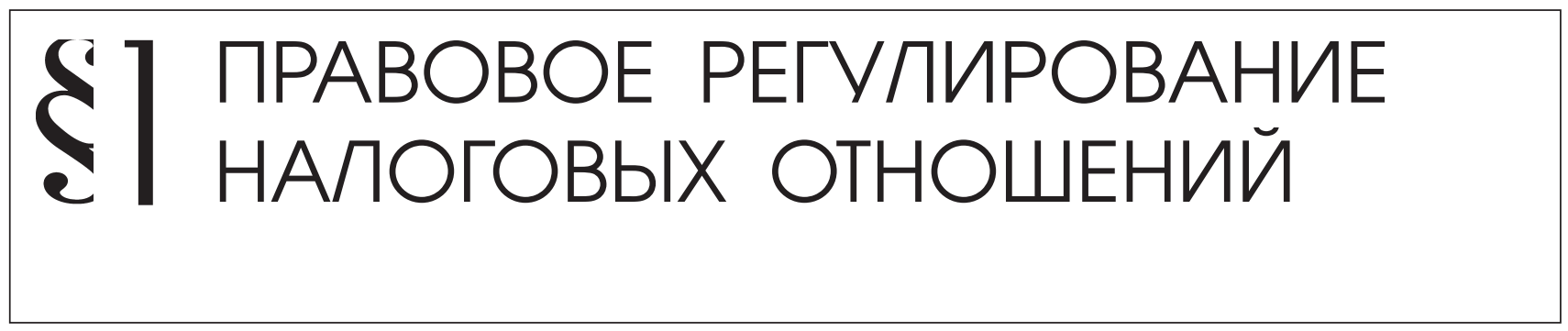

Ю.А. Шеховцова

\title{
ИСПОЛЬЗОВАНИЕ НАЛОГОВЫХ ИНСТРУМЕНТОВ ОБЕСПЕЧЕНИЯ ИНВЕСТИЦИОННОЙ БЕЗОПАСНОСТИ В РОССИЙСКОЙ ФЕДЕРАЦИИ
}

Аннотация: В статье исследована роль налоговых инструментов в обеспечении инвестиционной безопасности Российской Федерации. Установлено, что эти инструменты используются крайне нерационально. Их применение ведет к неоправданно большим налоговым изъятиям из дохода предприятий, что служит причиной хронической нехватки средств, необходимых для модернизации производства, его технического перевооружения, для внедрения новых технологий. Кроме того, налоговые инструменты не дают значимых преференций участникам инвестиционной деятельности, не создают стимулов для наращивания инвестиционных вложений в экономику, для обновления материально-технической базы национального хозяйства, не способствуют укреплению инвестиционной безопасности государства. Выявлены причины нерационального использования указанных инструментов. Предложены рекомендаџии по совершенствованию механизма их практического использования.

Ключевые слова: Экономика, инвестиции, безопасность, налоговые инструменты, функциии налогов, налоговая нагрузка, налоговые льготы, инвестиционный налоговый кредит, налогообложение дивидендов, инвестиционная активность

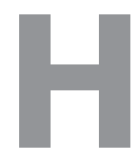

и для кого не секрет, что материально-техническая база российской экономики находится на сегодняшний день в плачевном состоянии. Степень износа основных производственных фондов приближается к 50\% (по отдельным отраслям - к $70 \%$ ). Средний возраст машин и оборудования достигает 13 лет. Пятая часть основных производственных фондов полностью изношена. На долю шестого технологического уклада приходится менее $1 \%$ технологий, на долю пятого - не более 10\%. Для сравнения: в США средний возраст машин и оборудования не превышает 6-7 лет ${ }^{1}$, доля шестого технологического уклада составляет 5\%, доля пятого $-60 \%{ }^{2}$.

\footnotetext{
${ }^{1}$ Table 1.9. Current-Cost Average Age at Yearend of Fixed Assets and Consumer Durable Goods / U.S. Department of Commerce. Bureau of Economic Analysis. URL: http:// www.bea.gov/iTable/iTable.cfm?ReqID=10\&step=1 (дата обращения 05.12.2012).

${ }^{2}$ Каблов Е.Н. Курсом в 6-ой технологический уклад / Нанотехнологическое общество России (HOP). URL: http://www.ntsr.info/science/reviews/1767.htm (дата обращения 05.12.2012).
} 


\section{Налоги и налогообложение - №3(105) • 2013}

Технологическое отставание нашей страны от США и других экономически развитых стран служит причиной ее низкой конкурентоспособности на мировом рынке. Низкая конкурентоспособность не позволяет нашему государству в полной мере реализовать свои экономические интересы. Ущемление экономических интересов Российской Федерации порождает угрозы ее устойчивому развитию, независимости, суверенитету.

Именно поэтому одной из неотложных задач российского государства является достижение и поддержание приемлемого уровня обеспеченности современными высокотехнологичными средствами производства, иными словами, достижение и поддержание инвестиционной безопасности.

Для решения данной задачи органы государственного управления располагают широким арсеналом средств, в число которых входят и налоговые инструменты регулирования экономики. Причина, по которой автор относит эти инструменты к средствам обеспечения инвестиционной безопасности, состоит в следующем.

Налоги помимо фискальной и контрольной функции выполняют также регулирующую и перераспределительную функции. Благодаря наличию этих функций, государство с помощью налоговых инструментов может воздействовать на макроэкономические пропорции, в том числе на пропорции между потреблением и сбережением, между тезаврацией и инвестированием, между вложениями в финансовые и реальные активы. Осуществляя такое воздействие, государство может вызвать рост инвестиционной активности хозяйствующих субъектов, обеспечить приток инвестиций в реальный сектор экономики, укрепить собственную инвестиционную безопасность.

Наше государство, как и любое другое, располагает налоговыми инструментами обеспечения инвестиционной безопасности и активно использует их на практике. Почему же, несмотря на это, уровень инвестиционной безопасности нашей страны на протяжении ряда лет остается крайне низким? Может быть потому, что эти инструменты используются нерационально? Если это так, то какие меры необходимо предпринять, чтобы повысить эффективность использования этих инструментов? Поиску ответов на эти вопросы и будет посвящена настоящая статья.

Итак, к налоговым инструментам обеспечения инвестиционной безопасности государства следует отнести ряд норм налогового права, реализация которых оказывает непосредственное влияние на инвестиционную активность хозяйствующих субъектов. В первую очередь к этим нормам следует отнести те положения налогового законодательства, которые устанавливают налоги на бизнес и регламентируют порядок их уплаты, в частности, определяют круг субъектов налогообложения, его объекты, величины налоговых ставок, сроки уплаты налогов, налоговые льготы.

При всем многообразии налоговых инструментов обеспечения инвестиционной безопасности все они могут быть объединены в две группы. К первой группе можно отнести инструменты, предназначенные для регулирования общей налоговой нагрузки на бизнес ${ }^{3}$, ко второй - инструменты, предназначенные для ее перераспределения между отдельными категориями налогоплательщиков.

В нашей стране инструменты первой групnы являются чрезвычайно действенными средствами регулирования инвестиционной активности хозяйствующих субъектов. Действенность этих инструментов объясняется наличием тесной зависимости инвестиций в основной капитал от величины общей налоговой нагрузки на бизнес (табл. 1).

\footnotetext{
${ }^{3}$ Под налоговой нагрузкой на бизнес в настоящей статье будем пронимать отношение налоговых отчислений финансовых и нефинансовых корпораций к ВВП, созданному этими институциональными секторами.
} 
Налоговая нагрузка на бизнес и инвестициии в основной капитал в Российской Федерации ${ }^{4}$

\begin{tabular}{|c|c|c|c|c|c|c|c|}
\hline & 2003 & 2004 & 2005 & 2006 & 2007 & 2008 & 2009 \\
\hline $\begin{array}{l}\text { Налоговые платежи } \\
\text { организаций, млрд. } \\
\text { руб. }\end{array}$ & 2620,5 & 3458,2 & 4017,6 & 4952,5 & 5944,0 & 7131,2 & 6085,1 \\
\hline $\begin{array}{l}\text { ВВП, произведенный } \\
\text { в секторе финансо- } \\
\text { вых } \\
\text { и нефинансовых кор- } \\
\text { пораций, млрд. руб. }\end{array}$ & 8949,7 & 11503,6 & 14427,4 & 17868,3 & 22347,2 & 27849,1 & 25435,1 \\
\hline $\begin{array}{l}\text { Налоговая нагрузка } \\
\text { на бизнес, \% }\end{array}$ & 29,3 & 30,1 & 27,8 & 27,7 & 26,6 & 25,6 & 23,9 \\
\hline $\begin{array}{l}\text { Инвестиции в основ- } \\
\text { ной капитал в теку- } \\
\text { щих ценах, } \\
\text { млрд. руб. }\end{array}$ & 2186 & 2865 & 3611 & 4730 & 6716 & 8782 & 7976 \\
\hline
\end{tabular}

О том, что такая зависимость действительно существует, свидетельствуют коэффициенты корреляции, детерминации и дуговой эластичности.

Так, коэффициент корреляции между инвестициями в основной капитал и налоговой нагрузкой на бизнес в анализируемый период времени составил -0,91. Такая величина коэффициента корреляции означает, что между этими показателями существует очень тесная обратная зависимость.

$$
E_{T}^{I}=\frac{I_{2009}-I_{2003}}{T_{2009}-T_{2003}} \times \frac{T_{2003}+T_{2009}}{I_{2003}+I_{2009}}=\frac{7976-2186}{23,9-29,3} \times \frac{29,3+23,9}{2186+7976}=-5,6,
$$

где $I_{2003}-$ инвестиции в основной капитал в 2003 году;

$I_{2009}-$ инвестиции в основной капитал в 2009 году;

$T_{2003}$ - налоговая нагрузка на бизнес в 2003году;

$T_{2009}$ - налоговая нагрузка на бизнес в 2009 году.

\footnotetext{
${ }^{4}$ Федеральная служба государственной статистики. URL: http://www.gks.ru/wps/wcm/connect/rosstat/rosstatsite/ main/ (дата обращения: 5.12.2012).
} 


\section{Налоги и налогообложение - №3(105) • 2013}

Величина этого коэффициента, взятая по модулю, существенно превышает единицу. Такое значение коэффициента дуговой эластичности свидетельствует о том, что инвестиции в основной капитал хорошо реагируют на изменение налоговой нагрузки на бизнес: снижение последней на один процент вызывает увеличение инвестиций в основной капитал на 5,6\%.

Тесная зависимость между инвестициями в основной капитал и налоговой нагрузкой на бизнес позволяет государству управлять инвестиционной активностью хозяйствующих субъектов, манипулируя первой группой налоговых инструментов обеспечения инвестиционной безопасности.

Чтобы ответить на вопрос о том, насколько рационально используются эти инструменты, необходимо выяснить, соответствует ли фактическая налоговая нагрузка на бизнес, установленная с их помощью, оптимальной нагрузке 5 . Для этого необходимо знать величину последней.

Если не принимать в расчет никакие иные функции налогов кроме функции обеспечения инвестиционной безопасности, оптимальным значением налоговой нагрузки на бизнес следовало бы признать ее нулевое значение. В самом деле, из обратной зависимости между объемом инвестиций в основной капитал и налоговой нагрузкой на бизнес следует, что максимум инвестиционных вложений достигается при полном отсутствии налогов.

Однако функция обеспечения инвестиционной безопасности государства не должна реализовываться в ущерб другим функциям налогов, в частности, фискальной функции.

\footnotetext{
5 Анализ соответствия фактической и оптимальной налоговой нагрузки на бизнес в настоящей работе производится в условиях 2009 года, поскольку, данные, необходимые для расчета фактической налоговой нагрузки на бизнес для более поздних периодов времени, еще не опубликованы.
}

Помимо стимулирования инвестиционной деятельности и поддержания приемлемого уровня обеспеченности современными высокотехнологичными средствами производства государство должно осуществлять налоговые изъятия для финансового обеспечения своего функционирования.

Поэтому минимизация налоговой нагрузки на бизнес в целях достижения и поддержания инвестиционной безопасности государства должна осуществляться с учетом определенных ограничений, связанных с необходимостью формирования доходной части государственного бюджета. Характер этих ограничений во многом зависит от того, какие фискальные цели ставит перед собой государство - максимизация налоговых поступлений в бюджет, обеспечение их достаточности для покрытия заданного объема государственных расходов и т.п.

Для нашего государства ключевой фискальной целью в последние годы было поддержание сбалансированности бюджетов всех уровней бюджетной системы. Об этом неоднократно упоминалось в Основных направлениях налоговой и бюджетной политики на очередной финансовый год. Условие сбалансированности доходов и расходов консолидированного бюджета Российской Федерации будем рассматривать в качестве ограничения минимизации налоговой нагрузки на бизнес.

Используя это ограничение, можно построить алгоритм определения оптимальной величины налоговой нагрузки на бизнес. Он будет состоять из двух этапов.

Этап первый: необходимо установить все значения налоговой нагрузки на бизнес, при которых налоговые поступления в бюджет позволяют обеспечить равенство государственных доходов и расходов. Выполнение этого этапа алгоритма обеспечивает соблюдение фискальных интересов государства. 
Этап второй: из значений, полученных на предыдущем этапе, необходимо отобрать минимальное, это и будет оптимальная налоговая нагрузка на бизнес. Выполнение этого этапа алгоритма обеспечивает соблюдение интересов инвестиционной безопасности государства.

Чтобы найти значения налоговой нагрузки на бизнес, при которых обеспечивается равенство доходов и расходов консолидированного бюджета (первый этап алгоритма), построим регрессионную модель, описывающую зависимость налоговых платежей корпораций от их налогового бремени. Как известно, эта зависимость носит полиномиальный характер и в общем виде описывается уравнением вида:

$$
y=a+b_{1} x^{2}+b_{2} x
$$

где $y$ - зависимая переменная (налоговые поступления в бюджет);

$x$ - независимая переменная (налоговая нагрузка);

$a, b_{1}, b_{2}$ - коэффициенты уравнения (константы).

Чтобы найти коэффициенты уравнения (2), подвергнем регрессионному анализу два динамических ряда данных: данные о величине налоговой нагрузки на бизнес и данные о величине налоговых платежей, осуществляемых организациями (табл. 1). Предварительно эти динамические ряды необходимо проверить на наличие в них тренда (если он присутствует, регрессионный анализ даст заведомо ложные результаты).

Расчет коэффициентов автокорреляции первого порядка подтвердил предположение о наличии тренда в указанных динамических рядах: для ряда, элементами которого являются данные о налоговой нагрузке на бизнес, этот коэффициент со- ставил 0,86; для ряда, элементами которого являются данные о величине налоговых платежей организаций, этот коэффициент составил 0,87 .

Чтобы устранить тренд в анализируемых динамических рядах, воспользуемся методом включения фактора времени в модель регрессии. Тогда уравнение (2) примет вид:

$y=a+b_{1} x^{2}+b_{2} x+b_{3} t$,

где $t$ - номер временного интервала, область определения этой переменной [1;7], ее значение, равное 1, соответствует 2003 году, равное 7, - 2009 году;

$b_{3}$ - коэффициент уравнения (константа).

Этот и другие коэффициенты, найденные методом регрессионного анализа и подставленные в уравнение (3), позволяют получить следующую модель зависимости налоговых платежей организаций от налоговой нагрузки и времени:

$y=-65504,64-75,97 x^{2}+4505,98 x+1073,41 t$

О том, что коэффициенты регрессионной модели (4) подобраны удачно, свидетельствуют такие статистики как коэффициент детерминации, близкий к единице и равный 0,954; критерий Фишера, равный 20,767 и превышающий свое критическое значение $(5,41)$.

Из уравнения (4) найдем значения налоговой нагрузки, при которых величина налоговых платежей организаций в каждый из анализируемых периодов времени (с 2003 по 2009 год) была бы достаточна для обеспечения равенства между государственными доходами и расходами. При этом будем исходить из следующих допущений. 


\section{Налоги и налогообложение - №3(105) • 2013}

Первое: расходы и неналоговые доходы государства являются экзогенно заданными параметрами, поэтому равенство между расходной и доходной частями консолидированного бюджета в модели достигается исключительно за счет корректировки налоговых доходов государства.

Второе: налоговая нагрузка физических лиц является экзогенно заданным чины налоговых платежей организаций. Чтобы обеспечить эту сбалансированность, платежи организаций будем увеличивать на величину бюджетного дефицита в те периоды времени, когда бюджет сводился с дефицитом; и сокращать на величину бюджетного профицита в те периоды, когда бюджет сводился с профицитом (табл. 2).

Таблица 2

Консолидированный бюджет Российской Федераџии, млрд. руб. ${ }^{6}$

\begin{tabular}{|c|c|c|c|c|c|c|c|}
\hline & 2003 & 2004 & 2005 & 2006 & 2007 & 2008 & 2009 \\
\hline Доходы & 4138,7 & 5429,9 & 8579,6 & 10625,8 & 13368,3 & 16003,9 & 13599,7 \\
\hline Расходы & 3964,9 & 4669,7 & 6820,6 & 8375,2 & 11378,6 & 13991,8 & 16048,3 \\
\hline $\begin{array}{c}\text { Дефицит (-), } \\
\text { профицит (+) }\end{array}$ & 173,8 & 760,2 & 1759,0 & 2250,6 & 1989,7 & 2012,1 & $-2448,6$ \\
\hline
\end{tabular}

При сделанных допущениях переменная $x$ в уравнении (4) принимает следующие значения (табл. 3).

Таблища 3

Значения налоговой нагрузки на бизнес, при которых достигается сбалансированность консолидированного бюджета Российской Федераџии, \%

\begin{tabular}{|c|c|c|c|c|c|c|}
\hline 2003 & 2004 & 2005 & 2006 & 2007 & 2008 & 2009 \\
\hline 26,823 & 26,494 & 24,187 & 23,475 & 23,669 & 23,77 & 27,699 \\
\hline 33,244 & 32,818 & 35,125 & 35,837 & 35,644 & 35,542 & 31,613 \\
\hline
\end{tabular}

параметром, поэтому сбалансированность доходов и расходов консолидированного бюджета в модели достигается исключительно за счет изменения вели-

\footnotetext{
${ }^{6}$ Федеральная служба государственной статистики. URL: http://www.gks.ru/wps/wcm/connect/rosstat/rosstatsite/ main/ (дата обращения: 5.12.2012)
}

Переходим ко второму этапу алгоритма определения оптимальной налоговой нагрузки на бизнес, в ходе которого из двух корней уравнения (4), найденных для каждого периода рассматриваемого временного интервала, отбираем минимальный. Отобранные значения налоговой нагрузки на бизнес и есть ее оптимальные значения. 
Правовое регулирование налоговых отношений

Сопоставим эти значения с фактической величиной налогового бремени предприятий (рис. 1).
Итак, фактическая налоговая нагрузка на бизнес в анализируемый период времени превышала свое оптимальное значение в среднем

Puc. 1

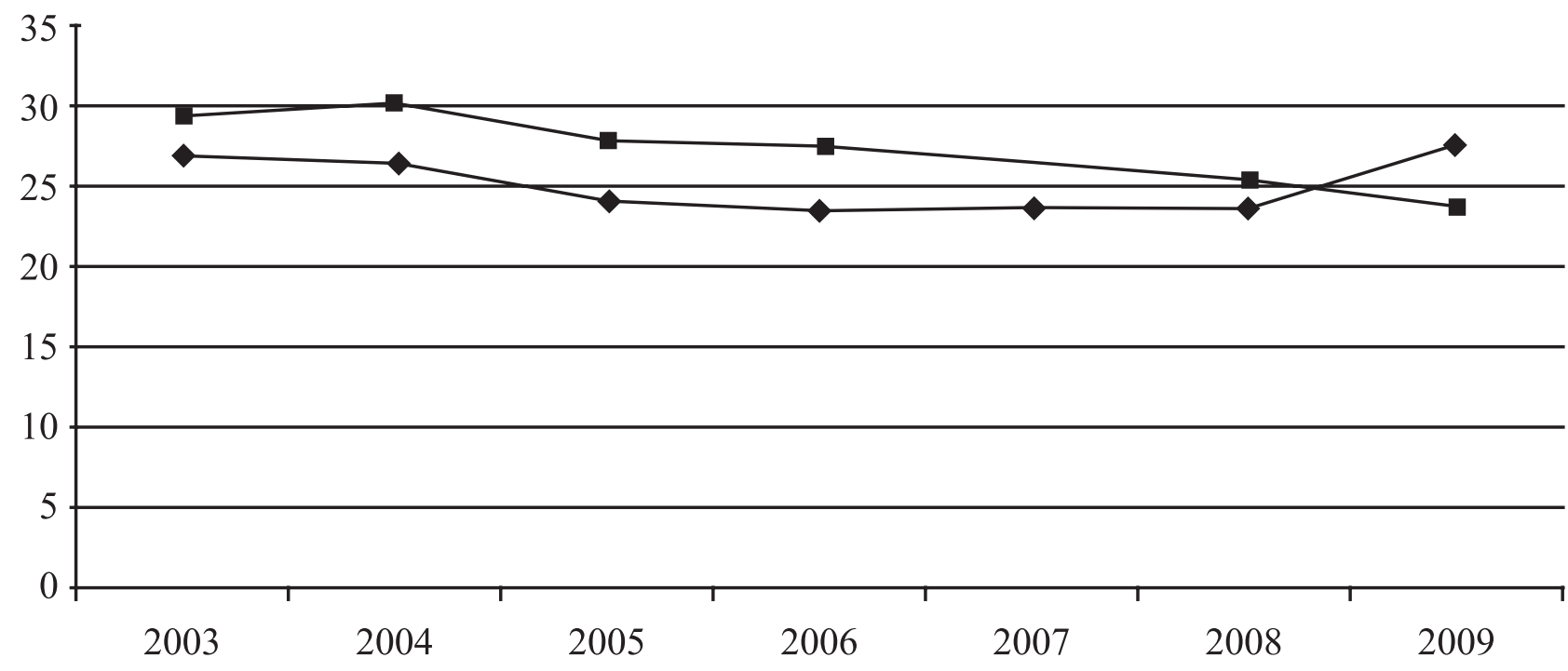

—-Оптимальная налоговая нагрузка

Как видим, фактическая налоговая нагрузка на бизнес на протяжении почти всего рассматриваемого временного интервала превышала свое оптимальное значение. Исключение составил лишь 2009 год, в котором фактическая налоговая нагрузка оказалась ниже оптимальной на 3,8\%. Однако это снижение налогового бремени - всего лишь результат экстренных антикризисных мер, например, снижения налога на прибыль с 24 до 20\%. Считать это и некоторые другие налоговые послабления, сделанные в 2009 году, началом новой долгосрочной тенденции снижения налогового бремени предприятий нельзя. Нельзя по той причине, что уже в 2010 году правительством были предприняты диаметрально противоположные меры, вызвавшие кардинальное увеличение налогового бремени предприятий, например, повышение ставок отчислений во внебюджетные фонды. на 3-4\%. Это обстоятельство говорит о том, что налоговые инструменты обеспечения инвестиционной безопасности, предназначенные для регулирования налоговой нагрузки на бизнес, использовались в данный период времени нерационально. Из-за их нерационального использования у предприятий в виде налогов изымались средства, по сумме превышающие фискальные потребности государства. Из-за неоправданных налоговых изъятий предприятия были лишены существенных финансовых ресурсов, необходимых им для технического перевооружения, обновления и расширения их материальной базы.

Если бы в рассмотренный период времени налоговая нагрузка на бизнес была снижена до оптимальной величины, фискальные интересы государства от этого не пострадали бы. В случае снижения налоговой нагрузки на бизнес до ее оптимального уровня главная 


\section{Налоги и налогообложение - №3(105) • 2013}

фискальная цель нашего государства, неоднократно декларируемая в Основах налоговой и бюджетной политики - сбалансированность бюджета, - была бы достигнута. При этом в распоряжении предприятий остались бы дополнительные средства для проведения модернизации производства, расширения материально-технической базы, а значит, и укрепления инвестиционной безопасности.

Далее рассмотрим налоговые инструменты второй груnпьl, то есть инструменты, предназначенные для перераспределения налоговой нагрузки между отдельными категориями налогоплательщиков. Очевидно, что применение этих инструментов в целях укрепления инвестиционной безопасности государства должно обеспечивать такое перераспределение налоговой нагрузки между экономическими субъектами, которое бы влекло снижение налогового бремени участников инвестиционной деятельности (особенно тех, которые функционируют в реальном секторе экономики). В самом деле, снижение налоговых издержек инвестирования делает последнее более привлекательными по сравнению с потреблением и тезаврацией, что ведет к наращиванию объема капитальных вложений, расширению материально-технической базы экономики, укреплению инвестиционной безопасности страны.

О рациональности использования инструментов второй группы можно судить по тем эффектам, которые возникают в результате реализации перераспределительной функции корпоративных налогов.

Из множества эффектов, порождаемых реализацией этой функции, для целей настоящего исследования представляют интерес лишь два - преимущества, предоставляемые участникам инвестиционной деятельности, и преимущества, предоставляемые реальным инвесторам.

Преимущества, которые получают участники инвестиционной деятельности в результате перераспределения налоговой нагрузки, являются в нашей стране достаточно скромными. В этом легко убедиться, если проанализировать льготы по налогу на прибыль - одному из основных корпоративных налогов, величина платежей по которому составляет треть всех налоговых платежей организаций. Как показали результаты проведенных расчетов, величина налоговых потерь государства, связанных с предоставлением льгот по этому налогу, в 2006-2008 годах не превышала 4\%, в 2009-2011 - 10\% его начисленной суммы (табл. 4).

Таблицьа 4 Налог на прибыль организаций и потери государства, связанные с предоставлением льгот по этому налогу в Российской Федерации

\begin{tabular}{|l|c|c|c|c|c|c|}
\hline & 2006 & 2007 & 2008 & 2009 & 2010 & 2011 \\
\hline $\begin{array}{l}\text { Сумма исчисленного налога на при- } \\
\text { быль, млрд. руб. }\end{array}$ & 1558,9 & 2091,2 & 1988,9 & 1379,4 & 1730,4 & 2097,5 \\
\hline $\begin{array}{l}\text { Сумма недопоступления налога на } \\
\text { прибыль организаций в связи с пре- } \\
\text { доставлением льгот, млрд. руб. }\end{array}$ & 58,7 & 79,1 & 78,9 & 104,0 & 163,1 & 162,1 \\
\hline
\end{tabular}

\footnotetext{
${ }^{7}$ Отчет о налоговой базе и структуре начислений по налогу на прибыль организаций / Федеральная налоговая служба Российской Федерации. URL: http://www.nalog. ru/nal_statistik/forms_stat/ (дата обращения 07.12.2012).
} 
Правовое регулирование налоговых отношений

Недопоступление налога на прибыль организаций в связи с предоставлением льгот, в процентах к сумме начисленного налога на прибыль организаций

Таким образом, предприятиям, которые воспользовались льготами по налогу на прибыль, за указанный период времени удалось сэкономить в среднем всего лишь $6 \%$ средств, предназначенных для исполнения их обязательств по уплате данного налога.

Обратим внимание на то, что в сумме недопоступления налога на прибыль организаций в связи с предоставлением льгот, учтены не только инвестиционные, но и все прочие льготы по данному налогу. Это обстоятельство дает основание предположить, что средняя экономия предприятий по налогу на прибыль, возникающая вследствие предоставления им инвестиционных льгот, в 2006-2011 годах была гораздо меньше 6\%.

Что касается экономии, которую участники инвестиционной деятельности получили по другим корпоративным налогам, то результаты произведенных расчетов показали - эта величина того же порядка, что и величина экономии по налогу на прибыль.

Преимущества, которые получают реальные инвесторы в результате перераспределения налоговой нагрузки, тоже являются весьма скромными из-за того, что в налоговом законодательстве Российской Федерации предусмотрены единые подходы к налогообложению доходов, полученных от производственных и финансовых инвестиций.

Примером недифференцированного подхода к налогообложению доходов, полученных в реальном и финансовом секторах экономики, служит налогообложение дивидендов. В нашей стране этот вид инвестиционного дохода облагается налогом по единой 9\%-ой ставке независимо от того, по каким ценным бумагам он получен - по акциям предприятий реального сектора экономики или по краткосрочным спекулятивным ценным бумагам.

Совершенно иные подходы к налогообложению дивидендов сложились в США, в развитых европейских и быстро развивающихся азиатских государствах. В этих странах инвесторы, осуществляющие вложения в реальный сектор экономики, пользуются существенными преференциями при налогообложении полученных ими доходов.

Например, в США компании, специализирующиеся на предоставлении инвестиций предприятиям малого бизнеса (так называемые SBIC - компании ${ }^{8}$ ), полностью освобождаются от уплаты налога на прибыль корпораций по полученным ими дивидендам 9 .

В Германии преференции, предоставляемые реальным инвесторам при налогообложении полученных ими дивидендов еще шире. В этой стране все дивиденды, выплачиваемые нефинансовыми корпорациями, освобождаются от уплаты налогов. Исключение составляют лишь дивиденды, полученные мелкими инвесторами, чья доля в акционерном капитале выплачивающей дивиденды компании, составляет менее $10 \%{ }^{10}$.

В Китае инвестиционные доходы на акции предприятий реального сектора экономики тоже полностью освобождены от

\footnotetext{
${ }^{8}$ Small business investment company.

${ }^{9}$ Internal Revenue Code / Cornell University Low School. URL: http://www.law.cornell.edu/uscode/text/26(дата обращения 12.12.2012).

${ }^{10}$ TAX CONSULT. Оффшоры. Инвестиции. Консалтинг. URL: http://taxc.com.ua/countries/germany/index.html (дата обращения 10.12.2012).
} 


\section{Налоги и налогообложение - №3(105) • 2013}

налогообложения. Правда воспользоваться этой льготой могут не все компании, а только те, что осуществляют свою деятельность в сфере сельского хозяйства и рыболовства. Данная льгота предоставляется также организациям, реализующим инфраструктурные инвестиционные проекты и проекты, направленные на охрану окружающей среды, водо-и энергосбережение ${ }^{11}$.

Почему же перераспределение налоговой нагрузки в нашей стране не дает значимых преференций субъектам инвестиционной деятельности, не стимулирует их наращивать инвестиционные вложения в реальный сектор экономики, не способствует модернизации ее материально-технической базы и укреплению инвестиционной безопасности государства?

Одну из причин нерационального распределения налоговой нагрузки в нашей стране, автор видит в стремлении российского государства к минимизации своих фискальных потерь, связанных с предоставлением налоговых льгот, в том числе и инвестиционных. При этом совершенно не принимается в расчет то, что предоставление преференций участникам инвестиционной деятельности ведет к росту их инвестиционной активности, увеличению объемов производства и налоговых поступлений в бюджет.

Из-за того, что государство не желает нести фискальные потери, связанные с предоставлением налоговых льгот, льготирование инвестиционной деятельности в Российской Федерации зачастую вообще не предусматривает снижения налоговой нагрузки на бизнес, оно лишь перераспределяет ее во времени, а также между отдельными участниками инвестиционной деятельности.

Перераспределение налоговой нагрузки во времени происходит, например, при предо-

\footnotetext{
${ }^{11}$ Кизимов А.С. Восток - дело тонкое, или о налогообложении в Китае // Российский налоговый курьер. 2009. № 15. С. 62-69. С. 66.
}

ставлении инвестиционного налогового кредита, который, по сути, является отсрочкой налоговых платежей по налогу на прибыль, а также по региональным и местным налогам. Предоставление этой отсрочки осуществляется на условиях возвратности и платности, то есть отсрочка налоговых платежей предусматривает в последующем поэтапное возмещение неуплаченных сумм налога и процентов по ним. Как видим, предоставление инвестиционного налогового кредита означает всего лишь перенос срока исполнения налоговых обязательств, но не освобождение от них.

Перераспределение финансовой нагрузки между отдельными участниками инвестиционной деятельности происходит, например, при предоставлении льготы по налогу на добавленную стоимость. Рассмотрим ее более подробно.

В соответствии со статьей 149 части второй Налогового кодекса Российской Федерации ${ }^{12}$ не подлежит налогообложению налогом на добавленную стоимость передача долей в уставном (складочном) капитале организаций, паев в паевых фондах кооперативов и паевых инвестиционных фондах, ценных бумаг и финансовых инструментов срочных сделок. Одновременно с передачей перечисленных выше активов предприятиеинвестор передает предприятию-реципиенту право на налоговый вычет, ранее предъявленный им при приобретении этих активов (статья 170 части второй Налогового кодекса Российской Федерации). При этом предприятие-инвестор восстанавливает (возмещает в бюджет) сумму указанного вычета: «восстановлению подлежат суммы налога в размере, ранее принятом к вычету, а в отношении

\footnotetext{
12 Налоговый кодекс Российской Федерации (часть вторая) [Электронный ресурс] : федер. закон Рос. Федерации от 5 августа 2000 года № 117-Ф3 : принят Гос. Думой Федер. Собр. Рос. Федерации 19 июля 2000 г. : одобр. Советом Федерации Федер. Собр. Рос. Федерации 26 июля 2000 г. Доступ из справ.- правовой системы «КонсультантПлюс».
} 
основных средств и нематериальных активов - в размере суммы, пропорциональной остаточной (балансовой) стоимости без учета переоценки» (статья 170 части второй Налогового кодекса Российской Федерации).

Данная льгота, безусловно, уменьшает нагрузку на предприятие- реципиента инвестиций, причем ее уменьшение происходит в силу двух причин. Первая: из-за того, что в стоимость передаваемых активов не включается налог на добавленную стоимость, обязательства реципиента перед инвестором оказываются меньше тех, которые бы он принял на себя в том случае, если бы рассматриваемая льгота ему не представлялась. Вторая: реципиенту предоставляется право на налоговый вычет по активам, при получении которых он не уплачивал налог на добавленную стоимость.

Однако одновременно со снижением налоговой нагрузки на реципиента происходит возрастание налоговой нагрузки на инвестора и происходит оно вследствие того, что инвестор теряет право на налоговый вычет по активам, при приобретении которых им в действительности был уплачен налог на добавленную стоимость.

Разумеется, определенные потери в форме неполученного налога со сделки по передаче активов несет и государство.

Таким образом, предоставление рассматриваемой налоговой льготы финансируется не только за счет государства, но и за счет инвестора. По сути, механизм предоставления этой льготы вызывает перераспределение нагрузки между государством, инвестором и реципиентом инвестиций уменьшает ее для реципиента и увеличивает для государства и инвестора. Возрастание налоговой нагрузки на инвестора не может не служить фактором, сдерживающим его инвестиционную активность.

Еще одной причиной нерационального распределения налоговой нагрузки являют- ся многочисленные недостатки российского налогового законодательства, из-за которых субъекты инвестиционной деятельности не могут воспользоваться теми немногими льготами, которые им предоставляет государство. В числе этих недостатков следует назвать наличие огромного количества труднопреодолимых барьеров, которые предприятию нужно преодолеть для получения той или иной налоговой льготы.

Примером льготы, для получения которой предприятию приходится преодолевать ряд существенных административных препятствий, является инвестиционный налоговый кредит.

В соответствии с Приказом ФНС РФ от 30 ноября 2011 года № ММВ-7-8/666@13, предприятие, претендующее на получение инвестиционного налогового кредита должно обратиться с соответствующим заявлением в управление ФНС России по субъекту Российской Федерации, на территории которого находится налоговый орган, в котором данное предприятие состоит на учете. Заявление предприятия должно быть согласовано с должностными лицами ряда органов государственной власти и их подразделений, в частности с должностными лицами отдела по урегулированию задолженности Управления ФНС России по субъекту Российской Федерации, Управления урегулирования задолженности и обеспечения процедур банкротства ФНС России, юридического отдела Управления ФНС России по субъекту Российской Федерации,

\footnotetext{
13 Об утверждении порядка рассмотрения налоговыми органами заявлений о предоставлении отсрочки, рассрочки, инвестиционного налогового кредита по уплате налога и сбора, а также пени и штрафа [Электронный ресурс] : приказ Федеральной налоговой службы Рос. Федерации от 30 ноября 2010 г. № ММВ-7-8/666@. Доступ из справ.-правовой системы «КонсультантПлюс».
} 


\section{Налоги и налогообложение - №3(105) • 2013}

финансовых органов субъектов Российской Федерации и муниципальных образований, Правового управления ФНС России.

Как видим, количество должностных лиц, от которых зависит окончательное решение о предоставлении предприятию инвестиционного налогового кредита, достаточно велико. Соответственно велико и количество согласований, которые должны быть произведены, прежде чем такое решение будет принято. Поэтому процедуру предоставления инвестиционного налогового кредита можно считать довольно сложной и бюрократизированной.

Поскольку критерии, которыми должны руководствоваться должностные лица вышеперечисленных органов государственной власти при принятии решения о выдаче инвестиционного налогового кредита, законодателем не определены, поскольку отсутствие таких критериев создает благоприятную среду для коррупционных правонарушений, процедуру предоставления данного кредита можно считать еще и коррупциогенной.

Сложность, бюрократизированность и коррупциогенность процедуры предоставления инвестиционного налогового кредита препятствуют его внедрению в российскую хозяйственную практику.

Итак, подводя итоги проведенного исследования, можно сделать следующие выводы.

Налоговые инструменты инвестиционной безопасности обеспечивают укрепление последней путем регулирования общей налоговой нагрузки на бизнес (инструменты первой группы), а также путем ее перераспределения между отдельными категориями налогоплательщиков (инструменты второй группы).

К сожалению, применение этих инструментов в нашей стране не дает ощутимых результатов: не вызывает роста инве- стиционной активности хозяйствующих субъектов, не способствует притоку инвестиционных ресурсов в реальный сектор экономики, не обеспечивает обновления и расширения материально-технической базы национального хозяйства. Основная причина низкой отдачи от применения налоговых инструментов обеспечения инвестиционной безопасности состоит в их нерациональном использовании.

Если говорить об инструментах первой группы, то они не обеспечивают соответствия фактической налоговой нагрузки на бизнес ее оптимальному уровню. Из-за этого налоговые изъятия из дохода предприятий в нашей стране являются неоправданно большими. Эти изъятия не оставляют частному сектору средств для модернизации производства, для обновления и расширения материально-технической базы, для внедрения новых технологий. Очевидно, что для коренного технического перевооружения российских предприятий и укрепления инвестиционной безопасности государства необходимо предпринять меры, направленные на снижение общей налоговой нагрузки на бизнес - приблизительно на 3-4\%.

Как и инструменты первой группы, инструменты второй группы используются в нашей стране крайне нерационально. Перераспределение налоговой нагрузки, осуществляемое с их помощью, не обеспечивает значимого снижения налогового бремени участников инвестиционной деятельности, не дает существенных преимуществ реальным инвесторам. Более того, в некоторых случаях перераспределение налоговой нагрузки подавляет инвестиционную активность бизнеса (речь идет о тех случаях, когда предоставление льгот одним субъектам инвестирования осуществляется за счет утяжеления налогового бремени других). Обобщая, можно сказать, что перераспреде- 
ление налоговой нагрузки, осуществляемое в настоящее время в нашей стране, не стимулирует инвестиционные вложения в реальный сектор экономики, не создает предпосылки для модернизации ее материально-технической базы, не способствует укреплению инвестиционной безопасности государства.

Причины нерационального распределения налоговой нагрузки между отдельными категориями налогоплательщиков в нашей стране состоят в стремлении государства к минимизации своих фискальных потерь, возникающих вследствие предоставления налоговых преференций участникам инвестиционной деятельности, а также в несовершенстве российского законодательства, устанавливающего многочисленные препятствия для получения инвестиционных налоговых льгот.

Очевидно, что для устранения этих причин, необходимо внести определенные корректировки в практику использования налоговых инструментов второй группы.

Во-первых, необходимо предоставить дополнительные преимущества участникам инвестиционной деятельности, особенно тем из них, кто осуществляет вложения в реальный сектор экономики.

Во-вторых, необходимо исключить случаи предоставления налоговых льгот одним участникам инвестиционной деятельности за счет других, поскольку это дестимулирует последних.

В-третьих, необходимо упростить, дебюрократизировать и декриминализировать процедуру предоставления налоговых льгот в нашей стране.

Реализация этих предложений позволила бы увеличить объем инвестиций в российскую экономику, обновить и расширить материально-техническую базу национального хозяйства, укрепить инвестиционную безопасность государства.

\section{Библиография:}

1. Каблов Е.Н. Курсом в 6-ой технологический уклад / Нанотехнологическое общество России (HOP). URL: http://www.ntsr. info/science/reviews/1767.htm (дата обращения 05.12.2012).

2. Кизимов А.С. Восток - дело тонкое, или о налогообложении в Китае // Российский налоговый курьер. 2009. № 15. С. 62-69.

3. Налоговый кодекс Российской Федерации (часть вторая) [Электронный ресурс] : федер. закон Рос. Федерации от 5 августа 2000 года № 117-Ф3 : принят Гос. Думой Федер. Собр. Рос. Федерации 19 июля 2000 г. : одобр. Советом Федерации Федер. Собр. Рос. Федерации 26 июля 2000 г. Доступ из справ.- правовой системы «КонсультантПлюс».

4. Об утверждении порядка рассмотрения налоговыми органами заявлений о предоставлении отсрочки, рассрочки, инвестиционного налогового кредита по уплате налога и сбора, а также пени и штрафа [Электронный ресурс] : приказ Федеральной налоговой службы Рос. Федерации от 30 ноября 2010 г. № ММВ7-8/666@. Доступ из справ.- правовой системы «КонсультантПлюс».

5. Отчет о налоговой базе и структуре начислений по налогу на прибыль организаций / Федеральная налоговая служба Российской Федерации. URL: http:/www.nalog.ru/ nal_statistik/forms_stat/ (дата обращения 07.12.2012).

6. Федеральная служба государственной статистики. URL: http://www.gks.ru/wps/ wcm/connect/rosstat/rosstatsite/main/ (дата обращения: 5.12.2012).

7. Internal Revenue Code / Cornell University Low School. URL: http://www.law.cornell. edu/uscode/text/26(дата обращения 12.12.2012). 


\section{Налоги и налогообложение - №3(105) • 2013}

8. Table 1.9. Current-Cost Average Age at Yearend of Fixed Assets and Consumer Durable Goods / U.S. Department of Commerce. Bureau of Economic Analysis. URL: http://www.bea. gov/iTable/iTable.cfm?ReqID $=10 \&$ step $=1$ (дата обращения 05.12.2012).

9. TAX CONSULT. Оффшоры. Инвестиции. Консалтинг. URL: http://taxc.com.ua/ countries/germany/index.html (дата обращения 10.12.2012).

\section{References (transliteration):}

1. Kablov E.N. Kursom v 6-oy tekhnologicheskiy uklad / Nanotekhnologicheskoe obshchestvo Rossii (NOR). URL: http://www.ntsr.info/ science/reviews/1767.htm (data obrashcheniya 05.12.2012).

2. Kizimov A.S. Vostok - delo tonkoe, ili o nalogooblozhenii v Kitae // Rossiyskiy nalogovyy kur'er. 2009. № 15. S. 62-69. 